\title{
Postmortem assay of digoxin by radioimmunoassay
}

\author{
DAVID W. HOLT AND JOHN G. BENSTEAD \\ From the Poisons Unit, Guy's Hospital, London SE1 and the Department of Pathology, Southport General \\ Infirmary, Southport, Lancs
}

SYNOPSIS Analysis of postmortem blood samples from patients previously on maintenance digoxin therapy suggests that the results are of value in assessing the degree of digitalization at the time of death. Control cases gave results within the normal therapeutic range whereas of six cases in which digoxin was suspected of being implicated in the death five had 'serum' digoxin levels above the therapeutic range. Differences in digoxin concentration were noted in blood collected from three sites in the body, and it is suggested that postmortem blood should be collected from the leg veins if assessment of antemortem digitalization is to be made.

The use of plasma and serum levels of digoxin in the therapeutic management of patients on maintenance doses of the drug is increasingly practised. Many workers in this field have found a statistical correlation between digoxin concentration and symptoms of digoxin toxicity (Smith et al, 1969; Beller et al, 1971). Experience in this laboratory agrees with that elsewhere in indicating that the majority of patients with plasma levels of digoxin in excess of $2 \mathrm{ng} / \mathrm{ml}$ show some symptoms of toxicity (Smith and Haber, 1970). The use of the rapid and sensitive radioimmunoassay for digoxin has enabled clinicians to evaluate the plasma or serum level of the drug in the light of other variables such as renal function and cation balance, and has led to a more precise administration of the drug in cases of equivocal toxicity (Oliver et al, 1971).

All pathologists are familiar with the problems of sudden death from cardiovascular causes. Necropsy may reveal coronary arteries in which one's principal surprise is that the patient should have survived for so long and in which the myocardium may show features ranging from no abnormality to fresh infarction or general or localized fibrosis of long standing. In many cases a characteristic history, together with the complete absence of suspicious circumstances, makes it reasonably certain that the patient has died from a cardiovascular cause, probably through the mechanism of fibrillation. When the patient has received digoxin before death there have been obvious clinical indications for its use, but it may be helpful to know the 'blood' digoxin level post mortem, especially where patho-

Received for publication 31 December 1974. gnomonic cardiovascular lesions are absent and there is no morbid anatomical cause of death.

The following preliminary findings are a postmortem assessment of cases taking into account the possibility of digoxin toxicity as a factor in the cause of death.

\section{Methods}

Serum digoxin levels were measured using radioimmunoassay with labelled tracers of either ${ }^{3} \mathrm{H}$ or 125I-digoxin.

PROCEDURE WITH ${ }^{3}$ H-DIGOXIN

To $250 \mu \mathrm{l}$ of 'serum' sample, or standard, $500 \mu \mathrm{l}$ of $0.067 \mathrm{M}$ phosphate buffer $\mathrm{pH} 7.6$ were added, followed by $50 \mu \mathrm{l}(1 \mathrm{ng})$ of ${ }^{3} \mathrm{H}$-digoxin specific activity $5 \mathrm{Ci} / \mathrm{mM}$ (NEN, Boston, USA) and $50 \mu \mathrm{l}$ of suitably diluted digoxin-specific antibody raised in this laboratory. Incubation was for $\mathbf{3 0}$ minutes at room temperature, after which $200 \mu \mathrm{l}$ of BSA coated charcoal in barbitone buffer was added. Five minutes later the mixture was centrifuged at $3000 \mathrm{~g}$ for 15 minutes and an aliquot of the supernatant was transferred to a glass scintillation vial. Ten $\mathrm{ml}$ of a dioxan-based scintillator were added, after which the vials were heated in a waterbath for 10 minutes at $60^{\circ} \mathrm{C}$ and then centrifuged for 5 minutes at $3000 \mathrm{~g}$. ${ }^{3} \mathrm{H}$ counting was carried out in a Packard model 3320 liquid scintillation spectrometer.

Correction for colour quench was effected by use of an internal standard of tritiated water.

The procedure using the ${ }^{125}$ I tracer was largely the same, but since the radiolabelled digoxin was of a 
higher specific activity - $500 \mathrm{Ci} / \mathrm{mM}$ (Wellcome Reagents Ltd, Beckenham, England) - sample volumes of $100 \mu \mathrm{l}$ were used with $50 \mu \mathrm{l}$ of labelled digoxin containing $200 \mathrm{pg}$. After charcoal addition and centrifugation an aliquot of the supernatant was transferred to a plastic tube for scintillation counting in an LKB/Wallac 80000 gamma sample counter.

Standards for the assay were prepared in fresh citrated human plasma in the range $0-4 \mathrm{ng} / \mathrm{ml}$ using a standard solution made from crystalline digoxin (Wellcome Reagents Ltd).

All standards were assayed in duplicate and samples in triplicate.

The iodinated tracer method was used preferentially as it was faster and required less counting time and no correction for colour quench. Samples assayed by both methods gave the same results to within $4 \%$.

\section{Results}

Sixteen necropsies in which the patient had been receiving digoxin therapy were investigated. Ten were regarded at necropsy as 'controls' in which there was no reason to regard digoxin as having played any part (other than beneficial!). In six cases there was a suspicion that digoxin might have been a contributory factor in the cause of death. All 16 patients had been on maintenance digoxin therapy for a considerable period before death.

The six suspicious cases could be divided into two groups, and these together with the controls were so designated at necropsy and before the results of analysis were known.

The classification of the suspicious cases into two groups comprised:

GROUP 1

In these cases there was a high degree of probability that digoxin was implicated in the cause of death.

Case $1 \mathrm{BW}$, a 62-year-old woman. $0.25 \mathrm{mg}$ digoxin daily. Slight mitral stenosis. Microscopy revealed small areas of fibrosis consistent with old rheumatic carditis. Death occurred in bed.

Case $2 \mathrm{AJ}$, a 74-year-old woman. $0.5 \mathrm{mg}$ digoxin daily. Heart weight $15 \mathrm{oz}$. Slight thickening of the left ventricle though representative sections showed no abnormal features. Death occurred in bed.

Case $3 \mathrm{JA}$, a 63-year-old man. $0.25 \mathrm{mg}$ digoxin daily. Moderate myocardial fibrosis. Heart chambers enlarged. Death sudden while ambulatory.

Case 4 RR, a 79-year-old man. $0.25 \mathrm{mg}$ digoxin daily. Heart weight $13 \mathrm{oz}$. Both lungs affected by emphysema. Death occurred suddenly while seated in a chair.
GROUP 2

In these cases there was a possibility that digoxin had been a contributory factor in the cause of death but there was reasonable inference from the organs and history that death could have resulted solely from a cardiovascular cause.

Case $1 \mathrm{ES}$, a 66-year-old woman. $0.0625 \mathrm{mg}$ digoxin daily. Heart weight $19 \mathrm{oz}$. Left ventricle thickened and much dilated. Death occurred in bed.

Case $2 \mathrm{AH}$, an 80-year-old woman. $0.25 \mathrm{mg}$ digoxin daily. Heart weight $14 \mathrm{oz}$. Dense patchy fibrosis in the posterior wall of the left ventricle. Moderate atheroma of the coronary arteries. Death occurred suddenly while seated.

Blood was collected from the femoral vein into a glass vial and was centrifuged at $3000 \mathrm{~g}$ for 5 minutes. The supernatant, designated 'serum', was then assayed for digoxin. The results for the analysis of digoxin are shown in table I.

It can be seen that cases in group 1 had markedly elevated digoxin levels, while in group 2 ES was in the therapeutic range (although a little high in relation to the daily dose) and $\mathrm{AH}$ was within the toxic range.

\begin{tabular}{lll}
\hline & Patient & Digoxin $(\mathrm{ng} / \mathrm{ml})$ \\
\hline Group 1 & & \\
& BW & $4 \cdot 0$ \\
& AJ & $7 \cdot 5$ \\
& JA & $5 \cdot 6$ \\
Group 2 & RR & $3 \cdot 5$ \\
& & \\
& ES & $1 \cdot 7$ \\
& AH & $2 \cdot 9$ \\
& & Mean 4.2 \\
\hline
\end{tabular}

Table I Serum digoxin concentrations-'suspect' deaths

CONTROL CASES

Cases were selected to check the possibility that postmortem levels of digoxin were, as a rule, abnormally high. Samples were collected from digitalized cases where the death was certified without hesitation, usually from a cardiovascular cause, and where there was no suggestion that digoxin might be implicated. To monitor an additional variable it was decided to collect blood from three sites in the body to see whether differences in drug concentration existed depending on the site of sampling. Blood samples were collected from the femoral vein by milking into the vial, from the right ventricle of the heart by opening it in situ and allowing the blood to flow into the vial, and from the neck by allowing venous blood to flow into the vial as the skin was reflected. 


\begin{tabular}{|c|c|c|c|}
\hline Patient & Heart & Neck & Leg \\
\hline \multicolumn{4}{|c|}{ Control cases } \\
\hline EC & 1.5 & 1.6 & 0.7 \\
\hline TD & 1.9 & $1 \cdot 7$ & 0.8 \\
\hline RN & $1 \cdot 3$ & $1 \cdot 3$ & 1.0 \\
\hline WL & 1.8 & $2 \cdot 0$ & 1.2 \\
\hline MC & 3.9 & $3 \cdot 8$ & 2.9 \\
\hline NS & $3 \cdot 7$ & $2 \cdot 5$ & $2 \cdot 1$ \\
\hline JB & $2 \cdot 0$ & 0.6 & 0.9 \\
\hline EH & $2 \cdot 0$ & $1 \cdot 6$ & 1.2 \\
\hline 18854 & 1.4 & $1 \cdot 3$ & $1 \cdot 1$ \\
\hline CB & $3 \cdot 3$ & $2 \cdot 0$ & 1.9 \\
\hline Mean & $2 \cdot 33$ & $1 \cdot 84$ & $1 \cdot 38$ \\
\hline \multicolumn{4}{|c|}{ 'Suspect' cases } \\
\hline $\mathbf{R} \mathbf{R}$ & $4 \cdot 2$ & $4 \cdot 0$ & 3.5 \\
\hline ES & $3 \cdot 7$ & 3.6 & 1.7 \\
\hline $\mathbf{A H}$ & $4 \cdot 0$ & $3 \cdot 8$ & $2 \cdot 9$ \\
\hline
\end{tabular}

Table II Serum digoxin concentrations $(\mathrm{ng} / \mathrm{ml})$

The results are shown in table II together with results for samples from all three sites obtained from three of our 'suspect' deaths.

Notably, in all cases but one, the level of digoxin in blood from the leg vein was markedly lower than the figures for the other two sites, and there was a tendency for that from the heart to be the highest of all. With the possible exception of patient MC, the digoxin level in blood from the leg was within the normal therapeutic range for the drug.

The results for samples collected from all three sites in 'suspect' deaths followed the same pattern as our 'control' cases.

There was a statistical difference between mean digoxin concentrations in blood from the leg and heart in our 'control' cases $(P<0.005$ Student's $t$ test) and between mean levels in our 'suspect' and 'control' cases for blood collected from the leg (figure).

The state of the samples obtained varied from those yielding a clear straw serum to those which were severely lysed, and it was thought prudent to evaluate the effect of haemolysis on the result given by radioimmunoassay.

Blood samples were drawn from two patients on maintenance digoxin therapy and from one volunteer taking no digoxin. An aliquot of the sample was heparinized and centrifuged while the remainder was subjected to ultrasonic shock treatment for $\mathbf{4 5}$ seconds using a Polytron PT200D homogenizer. The lysed blood was then centrifuged for $\mathbf{3 0}$ minutes at $25000 \mathrm{~g}$. The lysed blood, together with the plasma from the whole blood, was then assayed for digoxin using ${ }^{125}$ I-labelled digoxin with the results shown in table III.

The distribution coefficient for digoxin between red cell/plasma in humans is 0.95 (Abshagen et al,

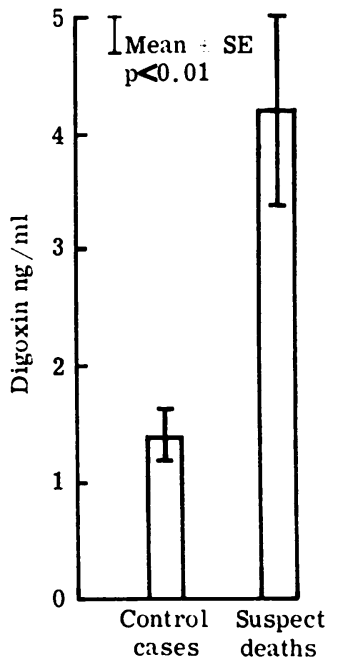

Figure Mean digoxin concentrations in blood collected from the leg.

\begin{tabular}{lll}
\hline Patient & Plasma & Lysed Blood \\
\hline 1 & $2 \cdot 1$ & 1.85 \\
2 & $1 \cdot 2$ & 1.05 \\
Control & Zero & Zero \\
\hline
\end{tabular}

Table III Effect of haemolysis on digoxin concentration $(\mathrm{ng} / \mathrm{ml})$

1971), and these results correlated well with the expected reduction in plasma level on complete haemolysis of the sample.

The results for the blank sample confirmed that no substances were released which interfered with the assay when haemolysis occurred. As an additional check, samples were collected from the heart, neck, and leg in a case for which there was no record of antemortem digoxin ingestion; all three samples were negative for digoxin.

Samples assayed by both the ${ }^{3} \mathrm{H}$ and ${ }^{125} \mathrm{I}$ tracer methods gave results which showed no statistical difference between the methods and which were similar to previous published results comparing the two tracers (Drewes and Pileggi, 1974).

\section{Discussion}

High levels of digoxin (above the normal therapeutic range) were encountered in postmortem blood collected from the leg in five of our six cases 
in which there was a suspicion that digoxin could have been implicated in the cause of death.

That these results represent genuinely high levels before death was borne out by our control cases in which levels within the normal therapeutic range for digoxin were encountered in blood taken from the leg.

The high levels obtained in cases from group 1 were well into the toxic range, and one case, A J, would qualify as an overdose. Such levels might constitute a lethal hazard since it is well documented that the toxic manifestations of digoxin include the precipitation of intractable congestive cardiac failure and the development of life-threatening arrhythmias (Chung, 1969; Fisch, 1971).

Our results also showed that there could be considerable variation in the digoxin concentration, depending upon the site from which blood is collected, with as much as $137 \%$ difference between blood from the heart and blood from the leg, the heart level being consistently higher.

It is possible that after death a new equilibrium between the blood and tissues is established, resulting in higher digoxin levels in blood collected from the heart, a tissue which per unit mass has a higher digoxin concentration than skeletal muscle (Doherty et al, 1967).

The finding that the drug level was almost always higher in blood collected from the neck compared with blood collected from the leg is not explained although antemortem differences in tissue distribution between those two areas seem to be the most likely explanation. Such postmortem differences have also been noticed for barbiturates (Gee et al, 1974) and paracetamol (Gee, 1974).

Our comparison of digoxin concentrations in plasma and haemolysed whole blood suggests that the degree of haemolysis of the samples does not significantly affect the result, nor does the process of lysing release compounds which interfere with the assay.

The implications of these findings are that the postmortem assay of digoxin can be used to investigate cases in which it is suspected that digoxin may have been a contributory factor in the cause of death. Levels above the normal therapeutic range appear to reflect elevated levels before death, but control samples suggest that blood from the leg should be used when retrospective use of the results is to be made.

On the basis of these results it appears that some patients who have been on digoxin therapy for some time may be 'at risk', having plasma levels of the drug well in excess of the normal therapeutic range. Such toxic plasma levels might well develop over a period of time as the result of a gradual reduction $\frac{C}{0}$ in renal function (probably the main determinant $\frac{\bar{c}}{2}$

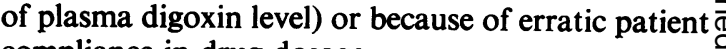
compliance in drug dosage.

Our study of 'suspect' deaths is continuing, together with an evaluation of digitalization among. $\overrightarrow{ }$ patients on long-term digoxin therapy in general $\vec{\overrightarrow{ }}$ practice.

We should like to thank Professor Gee, Department i of Forensic Medicine, University of Leeds, for $\infty$ samples from case 18854 and Dr Ian Calder, St George's Hospital, London for the sample and case $\stackrel{\infty}{\infty}$ details of patient JA. Our grateful thanks are due to응 Dr P. O'Gorman, Department of Chemical Pathol- ogy, Greenwich District Hospital for the use of $\subseteq$ gamma counting facilities and to R. A. Lloyd, Esq, HM Coroner.

\section{References}

Abshagen, U., Kewitz, H., and Rietbrock, N. (1971) Distribution of digoxin, digitoxin and ouabain between plasma and erythrocytes in various species. NaunynSchmiedeberg's Arch. exp. Path. Pharmak., 270, 105-115.

Beller, G. A., Smith, T. W., Abelmann, W. H., Haber, E., and Hood, W. B., Jr. (1971). Digitalis intoxication: 을 a prospective clinical study with serum level correlations. New Engl. J. Med., 284, 989-997.

Chung, E. K. (1969). Digitalis Intoxication. Excerpta Medica Foundation, Amsterdam.

Doherty, J. E., Perkins, W. H., and Flanigan, W. J. (1967). The distribution and concentration of tritiated digoxin in human tissues. Ann. intern. Med., 66, 116-124.

Drewes, P. A. and Pileggi, V. J. (1974). Faster and easier radioimmunoassay of digoxin. Clin. Chem., 20 (3), 343-347.

Fisch, C. (1971). Digitalis intoxication. J. Amer. med. Ass., 216, 1770-1773.

Gee, D. J. (1974). In The Poisoned Patient: the Role of the Laboratory: Ciba Foundation Symposium 26, p. 224. Elsevier, Excerpta Medica, North Holland.

Gee, D. J., Dalley, R. A., Green, M. A., and Perkins, L. A. N (1974). Post-mortem diagnosis of barbiturate poisoning. In Forensic Toxicology, edited by B. Ballantyne. Wright, Bristol.

Oliver, G. C., Parker, B. M., and Parker, C. W. (1971). Radioimmunoassay for digoxin. Amer. J. Med., 51, 186192.

Smith, T. W., Butler, V. P., Jr., and Haber, E. (1969). Determination of therapeutic and toxic serum digoxin concentrations by radioimmunoassay. New Engl. J. Med., 281, 1212-1216.

Smith, T. W. and Haber, E. (1970). Digoxin intoxication: the relationship of clinical presentation to serum digoxin concentration. J. clin. Invest., 49, 2377-2386. 